\title{
O ESTRANHAMENTO DO ESTUDANTE DE ENFERMAGEM À EPOCA DE PRESTAR O CUIDADO À PESSOA EM SOFRIMENTO MENTAL
}

Heitor Rocha de Mendonça PINHEIRO ${ }^{1}$

Alexandre Tourino MENDONÇA ${ }^{2}$

\author{
${ }^{1}$ Mestre de Ciências da Saúde, pela Universidade Vale do Rio Verde - UninCor. heitorrmp@ig.com.br \\ ${ }^{2}$ Professor Doutor, Universidade Vale do Rio Verde - UninCor. alexandretourino@gmail.com
}

Recebido em: 28/10/2014 - Aprovado em: 17/06/2015 - Disponibilizado em: 15/07/2015

\begin{abstract}
Resumo: Este trabalho propõe-se a compreender a complexidade da relação do estudante de Curso de Enfermagem, disciplina de Enfermagem na Saúde Mental e Psiquiátrica, no momento da aprendizagem para cuidar das pessoas com sofrimento mental, em vários dispositivos desse país. Desde os tempos históricos, pessoas com sofrimento mental, dementes, foram relegadas para lugares bloqueados e próximos aos cuidados de enfermagem. Este estudo mostra como os estudantes de enfermagem compreendem o processo de discussão sobre a loucura ao longo do tempo, usando questionários que lhes foram aplicados por períodos de estudo. $\mathrm{O}$ primeiro questionário foi aplicado aos que tiveram a parte teórica da disciplina, sem contato com as pessoas em sofrimento mental no campo de estágio. O segundo foi aplicado aos alunos que já haviam passado pela parte teórica e já estavam na parte prática da disciplina.
\end{abstract}

Palavras-chave: Cuidado de Enfermagem. Loucura. Estranhamento.

Abstract: This work proposes to understand the complexity of current student relationship nursing discipline in mental health and Psychiatry at the time of learning to take care of persons suffering mental on multiple devices that people. Since historical times, people suffering mental, demented, were relegated to the plans of seats locked and next nursing care. This study shows how the nursing students understand the process of discussion on the madness over time using questionnaires applied to students by periods of study. The first was applied to those who had the theoretical part of the discipline, without contact with people in mental suffering in the field of stage. The second questionnaire was applied to students who had already passed by the theoretical part and were already in the practical part of the discipline. Confirmed yet student nurses parameter to mental suffering person providing care in their practice.

Keywords: Nursing care. Madness.Estrangement.

\section{Introdução}

De acordo com estimativas internacionais e do Ministério da Saúde do Brasil, cerca de cinco milhões de indivíduos (3\% da população) com transtornos severos e persistentes necessitam de cuidadoscontínuos. Outros 20 milhões (12\% da população) apresentam transtornos menos graves com necessidade de atendimento eventual (BRASIL, 2004).

Os transtornos mentais e de comportamento são importantes problemas de saúde publica e frequentes em todas as sociedades e culturas, causando enorme incapacidade e padecimento às pessoas afetadas, além de considerável sofrimento aos familiares e amigos. Embora 
solidariedade e algum grau de assistência sejam oferecidos às pessoas fisicamente doentes, as atitudes relação às pessoas com sofrimento mental, muito frequentemente, incluem rejeição e estigmas.

Ao primeiro sinal de diferença no comportamento, ao longo da história, o homem tem recorrido aos cuidados médicos e, estes, por sua vez, levam ao internamento em locais fechados, hospícios, manicômios. Dessa forma, as pessoas com sofrimento mental - os loucos - por serem incompreendidos ou entendidos de diversas formas, foram mantidos isolados e distantes dos outros seres humanos, e os hospícios e manicômios, como instituições, continuaram fazendo parte do cotidiano do homem, apesar dos esforços em favor de sua extinção.

Dessa forma, alguns manicômios ainda funcionam tendo como importantes atores diversos profissionais de saúde, dentre eles, os enfermeiros, e "a violência do hospício concentrava-se no enfermeiro, encarregado de amarrar, conter ou adotar qualquer medida autoritária, a fim de manter a ordem" (ROCHA, 2008).

Segundo essa autora, em 1841, D. Pedro II determinou a construção de um hospício inaugurado em 1852.
Assim, a primeira instituição psiquiátrica brasileira a ser criada foi o Hospital Pedro II, situado na Praia Vermelha (na época era periferia do Rio de Janeiro), pertencente à Santa Casa. Essa instituição, seguindo o que era preconizado pelos doutores Pinel e Esquirol para o tratamento moral, isolava o doente mental em um espaço especialmente organizado para regular e normatizar sua vida.

Nele, os guardas 'ou enfermeiros', vigiavam os doentes, enquanto eram vigiados pelas irmãs de caridade que administravam o hospício (ROCHA, 2008).

No decorrer do curso de graduação de Enfermagem, os alunos têm contato com diferentes aspectos da loucura, nos mais variados contextos filosóficos, sociais, políticos, econômicos e culturais e seu percurso na história. Trabalha-se a questão da abordagem a ser feita em um processo terapêutico e respeitoso em relação às diferenças de cada pessoa em sofrimento mental.

No entanto, quando se aproxima o período em que os estudantes de enfermagem têm de se encontrar com as pessoas em sofrimento mental, eles ficam ansiosos e com medo do que encontrarão pelocaminho. Acredita-se que o estudante de enfermagem prestes 
a cuidar da pessoa em sofrimento mental, possa estar passando pelo processo de estranhamento diante de uma situação que se mostra estranha, misteriosa, enigmática e, até, extravagante.

Este trabalho tem como objetivo, avaliar o processo de preparação dos alunos do Curso de Enfermagem do Centro Universitário de Patos de Minas (UNIPAM), para o cuidado de enfermagem em Saúde Mental e Psiquiátrica, levando-se em conta alguns aspectos relativos à ocorrência de estranhamento em relação aos portadores de sofrimento mental.

$\mathrm{O}$ cuidado à pessoa em sofrimento mental é fundamental, para que ele possa deixar sua condição de sujeito estranho à comunidade e tornarse, mesmo com suas diferenças, uma pessoa que faça parte novamente da sociedade.

Os resultados obtidos na pesquisa serão utilizados em proposição de novo conteúdo programático na disciplina Saúde Mental e Psiquiátrica, possibilitando ao corpo docente uma reorientação do ensino de enfermagem e novas formas de condução dos elementos conceituais a serem repassados para a prática do lidar com os portadores de sofrimento mental.
Transtornos mentais e os serviços de saúde mental

Nos séculos XVIII e XIV, na Europa, os loucos e os "perturbadores da ordem" eram contidos e corrigidos em estabelecimentos como prisões, escolas, casas de correção e casas de loucos (PORTER, 1990 apud OLIVEIRA; ALESSI, 2005). De acordo com Castel (1978 apud OLIVEIRA; ALESSI, 2005), o isolamento dos internos do mundo exterior tinha como base uma imposição da ordem dos alienados, com a utilização de técnicas mais disciplinares que clínicas.

O século XIV caracteriza-se pelo movimento da medicalização e institucionalização das práticas

terapêuticas, nas quais o doente mental é isolado e tratado em grandes asilos (COLVERO; IDE; ROLIM, 2004). Dessa forma, o hospital psiquiátrico tem sido o único recurso para o tratamento de problemas psíquicos, contribuindo para a exclusão dos doentes mentais do convívio familiar e social, transferindo-os, permanentemente para a instituição hospitalar, na qual se perdia o convívio familiar (CAMPOS; SOARES, 2005).

Segundo Godoy e Bosi, o isolamento do doente mental é o instrumento mais marcante da 
psiquiatria, de acordo com a função social que o acompanha. Para essas autoras, "sobre o louco é exercida uma ação de violência, de múltiplas segregações: reclusão social ao abandono nu e imundo no pátio domanicômio, construindo-se a concepção de louco enquanto um ser perigoso, nefasto, incapaz, um 'nãoser', legitimando-se a condição de 'nãocidado', 'não-sujeito'(GODOY; BOSI, 2007).

No entanto, para Campos e Soares (2005), a partir da Segunda Guerra Mundial, ocorreram denúncias e debates dessa exclusão, gerando movimento de transformações das instituições psiquiátricas. Esse movimento foi orientado pelo esforço da desinstitucionalização, tendo em vista a desospitalizaçao e o retorno do doente ao convívio social (COLVERO; IDE; ROLIM, 2004).

A reforma psiquiátrica ocorrida no Brasil tem como pressuposto a desinstitucionalização dos portadores de transtornos mentais, indicando a criação de serviços de atenção como HospitaisDia, Núcleos ou Centros de Atenção Psicossocial (NAPS/CAPS), Serviços Residenciais Terapêuticos, Centros de Convivência e Cooperativas Sociais, de modo a evitar o isolamento $\mathrm{e}$ estigmatização ocorridos, principalmente, através da internação em hospitais psiquiátricos (CAMPOS; SOARES, 2005).

Os CAPS, dentro da atual política de saúde mental do Ministério da Saúde, são considerados estratégicos para a organização da rede de atenção em saúde mental, devendo ser territorializados e oferecer serviços que resgatem as potencialidades dos recursos comunitários à sua volta, bem como promover a reinserção do portador de sofrimento mental (BRASIL, 2004).

\section{O cuidado de enfermagem e saúde mental}

Segundo Machado, Moreira e Shoeller, "a enfermagem se apropria da, e recria a, finalidade do trabalho em saúde, direcionando sua atuação especialmente a três frentes: a criação de um ambiente terapêutico ideal; a administração de parcelas do ato médico; e a assistência de enfermagem" (MACHADO;

OREIRA; SCHOELLHER, 2002).

Existem duas formas de relações de cuidados: o cuidado em que o cuidador assume que a pessoa que é cuidada é capaz de realizar por si própria, e o cuidado em que o cuidador ajuda a outra pessoa a cuidar de si 
própria, favorecendo sua potencialidade de vir a ser, consistindo no cuidado autêntico (cuidar/cuidado). Os pressupostos básicos para o cuidar/cuidado humano, de acordo com Waldow, Lopes e Meyer são: o cuidar/cuidado pode ser efetivamente demonstrado e praticado somente de forma interpessoal; o cuidar/cuidado consiste de fatores que resultam da satisfação de certas necessidades humanas; o cuidar/cuidado inclui aceitar a pessoa não somente como ela é mas como ela virá a ser; o meio ambiente de cuidar/cuidado proporciona o desenvolvimento do potencial da pessoa, ao mesmo tempo que lhe permite escolher a melhor ação para si, em um tempo dado; o cuidar/cuidado é o foco central da enfermagem (WALDOW; LOPES; MEYER, 1995).

As diferentes maneiras de cuidar em enfermagem são determinadas pelas relações sociais de cada momento histórico. $\mathrm{Na}$ atualidade, o trabalho de enfermagem é especializado, dividido e hierarquizado entre auxiliares, técnicos e enfermeiros, de acordo com a complexidade de concepção e execução. No entanto, a enfermagem, embora detentora de autonomia dos auxiliares e técnicos subordina-se ao gerenciamento dos médicos. No que diz respeito à enfermagem psiquiátrica, esta surgiu no hospício, instituição disciplinar para reeducação do louco/alienado, onde o médico é detentor de autoridade a ser respeitada e os trabalhares de enfermagem são os executores das suas ordens disciplinares (OLIVEIRA; ALESSI, 2003).

Segundo Rocha (2008), "Pinel foi fundamental na mudança do estatuto do louco e autor de uma obra original"; para a enfermagem, o papel se destaca às pessoas que prestam os cuidados de enfermagem às outras pessoas com sofrimento mental e sempre esteve relacionado às orientações dominantes. Ainda segundo essa autora, "estudos mais recentes sobre essa época mostram que o trabalho de Pinel foi, em grande parte, inspirado em Jean-Baptiste Pussin - que ele conhecera" (ROCHA, 2008).

Pussin, segundo a autora, foi considerado por historiadores, o primeiro enfermeiro psiquiátrico no asilo francês de Bicetrê - uma figura até há pouco tempo silenciada (ROCHA, 2008), tendo deixado escritos sobre a organização da vida dos internos e os cuidados recomendados para sua recuperação.

Valorizava a bondade e a humanidade, pois havia observado que maltratar os loucos os induzia à violência e à agressão; entendia que maus tratos e castigos não poderiam 
reverter as ideias afetadas e afastava de suas funções os atendentes que não cumprissem essa norma. Em seus escritos, mostrava também que acreditava ser o sofrimento a causa das enfermidades e estimulava, entre os pacientes, o trabalho, a distração, a confiança, a liberdade possível e a imaginação de um futuro feliz (ROCHA,2008).

Até a década de 90, do século $\mathrm{XX}$, a ação de enfermagem psiquiátrica se concretizava, prevalentemente no campo administrativo do hospital psiquiátrico, de forma burocrática $\mathrm{e}$ baseada no modelo biológico (SILVA; FONSECA, 2005). No entanto, mesmo na atualidade, de acordo com Oliveira e Alessi (2003), grande parte do tempo do trabalho do enfermeiro é voltada para atividades administrativo/burocráticas, como organização do trabalho dos demais profissionais; sendo o trabalho do enfermeiro e o do corpo de técnicos e auxiliares de enfermagem, o meio/instrumento do trabalho médico e psicológico e as atividades de administração da assistência por parte dos enfermeiros como atuação técnicoassistencial especifica, não são prioritárias.

Dessa forma, na atualidade, o trabalho de enfermagem em saúde mental apresenta-se em transição entre a prática de cuidado hospitalar, com vistas ao controle do comportamento do portador de transtorno mental e à incorporação de princípios novos e desconhecidos, buscando adequação à uma prática interdisciplinar. De acordo com as autoras, existe um confronto teórico quanto ao portador de transtornos mentais que deixa de ser considerado um interno "doente mental" sendo contido e controlado, e passa a ser sujeito com 'sofrimento psíquico' que merece atendimento de suas necessidades psicossociais. No entanto, as intervenções do trabalho de enfermagem ainda estão mais direcionadas para a reafirmação da concepção organicista de objeto, do que para a incorporação de características psicossociais.

Na saúde mental, o paradigma atual mostra que a enfermagem deve estar preparada para novas possibilidades de exercer os cuidados, em dispositivos segundo a lógica de não encarceramento das pessoas em sofrimento mental.

No trabalho a ser desenvolvido pelos alunos em campo ou em sala de aula, diferentes possibilidades devem ser construídas para que o cuidado seja o que deve ser organizado, segundo a lógica da equipe e entendida como, "a equipe não pode organizar-se em torno 
do saber de uma determinada categoria profissional. $\quad \mathrm{Na} \quad$ saúde, tradicionalmente, este saber era aquele do médico: em torno dele, os outros profissionais tinham meramente um papel auxiliar. Contudo, nessa nova lógica de cuidados, nenhum saber ocupa o centro (SOUZA, 2006).

\section{O Estranhamento}

A palavra "estranhamento" pode ser definida de várias formas. De acordo com Ferreira "estranhar" é o ato de estranhar, de distanciar-se. A definição de estranhar, presente no dicionário, é:

Achar extraordinário, oposto aos costumes, ao hábito; achar estranho, achar diferente do que seria natural esperar-se, causar espanto, admiração a; surpreender, achar censurável; censurar, repreender, reparar em; notar, não se conformar com; não se familiarizar como, tratar com esquivança, com descortesia, esquivar-se de (pessoa desconhecida); chorar, ou manifestar timidez em presença de, ou repulsão a, esquivar-se; afastar-se (FERREIRA, 1975).

O termo "estranhamento" foi adotado pela Psicologia Social por influência da palavra inglesa estrangement, no sentido de distanciamento social, estágio intermediário entre a incompreensão e o conflito (CABRAL; NICK, 1974) significado assumido neste estudo.

$\mathrm{O}$ estudante de enfermagem se depara com a possibilidade de cuidar de pessoas com sofrimento mental, sendo necessário que a primeira parte do curso prepare o aluno para lidar com essas pessoas.

O estranho coloca-se como uma situação em que o estudante tem que dar conta. Cuidado a cuidado, no decorrer do estágio no mundo até então desconhecido da loucura.

"O conhecimento começa com o estranhamento. O primeiro passo da investigação filosófica é colocar-nos num estado no qual possamos perceber a estranheza de alguma coisa. Normalmente, não percebermos essa estranheza porque não prestamos atenção, mas, quando prestamos atenção, a estranheza aparece"(CARVALHO, 1998).

O estranho, o que não é familiar, é visto e presenciado pelos alunos nos períodos de contato com a saúde mental, com pessoas em sofrimento mental e devem lidar da maneira de cada um, com suas particularidades, a partir do conhecimento adquirido durante o curso que tem, em suas diversas possibilidades, o estágio em instituições que hoje se denominam 
substitutivas das internações em hospitais psiquiátricos. São importantes dispositivos no contato dos loucos com os alunos que, para tanto, necessitam de conhecimento prévio, adquirido durante os primeiros tempos do curso, mas nem sempre tem sido possível o estágio no CAPS, optando-se por trabalhar em grupos operativos nas unidades de saúde espalhadas pelo município.

Os estudantes de enfermagem, na época de prestar o cuidado às pessoas em sofrimento mental, demonstram nos seus atos de cuidar, os vários e, por vezes, incontidos manifestos de estranhamento ao psicótico, chegando até mesmo a não suportar e não suportar-se e, isso vai sendo superado no decorrer no curso em suas diversas abordagens.

Umheimlich, diria Freud, da nossa 'origem'. A palavra alemã Unheimlich - que tem duplo significado e ao mesmo tempo pode ser estranho e familiar - serviu para que Freud pensasse o que a filósofa portuguesa Fernanda Bernardo chamou de 'caráter abissal da existência'(RODRIGUES, 2009).

Essa pesquisa foi realizada no Centro Universitário de Patos de Minas (UNIPAM), uma instituição de ensino superior privado, instalada no município de Patos de Minas, região do Alto
Paranaíba, em Minas Gerais. O UNIPAM é composto pela Faculdade de Filosofia, Ciências e Letras (FAFIPA), Faculdade de Direito (FADIPA), Faculdade de Ciências Administrativas (FACIA), Faculdade de Ciências Agrárias (FACIAGRA) e Faculdade de Ciências da Saúde (FACISA).

Foram pesquisados os alunos do curso de enfermagem do UNIPAM, cuja carga horária totaliza 3.820 horas/aula, distribuídas em 3.080 horas/aula em disciplinas, 120 h/a em atividades complementares e 620 h/a em estágio supervisionado.

$\begin{array}{ccc}\text { Foram } & \text { elaborados } & \text { dois } \\ \text { questionários auto-aplicáveis, } & \text { com } \\ \text { questões } & \end{array}$
visavam avaliar o impacto das diversas possibilidades de cuidados ao portador de sofrimento mental apresentadas nas disciplinas do curso, bem como questões que possibilitaram constatar estranhamentos, medos e receios e a concepção de saúde mental que poderia dificultar o contato com o campo de trabalho e de como se vêem no processo de aprendizado. Para preservar a identidade dos participantes, não foi solicitada a identificação.

Foi elaborado ainda um questionário com questões abertas para 11 alunos, em uma parte da coleta. A 
maioria dos alunos está na idade 25 anos, época em as pessoas estão em plena construção de possibilidades de trabalho em suas vidas, de definições importantes em termos de profissionalização e ganho. É um período na vida das pessoas, como o "inicio de um curso, da vida profissional, o casamento e $\mathrm{o}$ nascimento dos filhos são momentos em que a pessoa se defrontar com situações desejadas, porém novas, desconhecidas e, por isso, geradoras de tensão" (ROCHA, 2008).

Ó juventude! Juventude! Se não se importa com nada, como se possuísse todos os tesouros do universo, até o luto lhe orna, é autossuficiente e atrevida; você diz: só eu

Vivo, olhem! E, no entanto, seus próprios dias correm e somem sem deixar rastros nem contas, e tudo dentro de si desaparece como cera ao sol, como neve... e quem sabe todo o segredo do seu encanto consiste não na possibilidade de tudo conseguir, mas na possibilidade de pensar que pode realizar tudo; consiste justo no que solta ao vento, forças que não saberia usar par qualquer outra coisa; naquilo que cada um de nós, a sério, considera-se perdulário, pressupõe que tem o direito de dizer: Oh,o que eu faria se não perdesse tanto tempo à toa (TURGUÊNIEV, 2008).

No curso de enfermagem em Saúde Mental e Psiquiátrica, os alunos têm contato com o desconhecido, com a loucura e o estranhamento se dá, justamente, pela não-familiaridade e pelas possibilidades de se trabalhar com um novo objeto de cuidados. Ainda, segundo ROCHA, "entretanto, um evento que é traumático para um indivíduo nem sempre vai produzir o mesmo efeito em outro; isto vai depender da maneira como ele é recebido, daquilo que ele significa para a pessoa ou para a família, ou seja, é algo da ordem da subjetividade" (ROCHA, 2008).

Quanto ao sexo, $87,7 \%$ dos participantes eram do sexo feminino, $10,8 \%$ do sexo masculino, sendo que podemos considerar um fato histórico "a entrada massiva das mulheres na indústria e em outras áreas como magistério e a enfermagem nascente, insere-se, então, num momento em que se desencadeia o que ela chama de "limpeza da imagem da mulher" (WALDOW; LOPES; MEYER, 1995).

A questão do gênero sempre teve uma importância considerável na formação da história da enfermagem e seu pressuposto, o cuidado. 
Historicamente, a enfermagem apresenta na grande maioria de seus trabalhadores, a presença das mulheres, pois segundo Machado, Moreira e Shoeller é importante destacar que um percentual superior a $85 \%$ do contingente de pessoal de Enfermagem é de mulheres. Pode-se perfeitamente compreender as manobras políticas e institucionais para justificar os baixos salários do pessoal de Enfermagem: elas são reflexos do sistema de valores do patriarcado que atribui à mulher papel secundário na estrutura e divisão de bens na sociedade (MACHADO; MOREIRA; SHOELLER, 2002).

Segundo esses autores, a questão das mulheres no trabalho da enfermagem é uma importante questão, pois a maioria delas assumiu historicamente as nuances de gênero, estruturantes das relações de trabalho na saúde, a divisão sexual das atividades está presente no conjunto dos cuidados e do trabalho hospitalar.

\section{Preparação dos alunos para a assistência em saúde mental}

Quando questionados se consideravam suficiente a preparação que receberam no curso de

Enfermagem para atuar na saúde mental, 69,2\% consideraram que NÃO,
29,2\% que SIM, o que mostra serem necessários ajustes no conteúdo ministrado e na própria divisão das partes da disciplina, já que os alunos não se mostraram adequadamente preparados e, que, certamente, poderão vir a necessitar de cursos posteriores à graduação, o que pode ser considerado um processo normal nas etapas de estudo.

Percebeu-se que a maior parte dos alunos (47,7\%), mas não a maioria, considerou que a separação do curso em blocos I e II de conhecimento facilitava a compreensão do assunto, mas por outro lado, apenas 4,6\% deles consideraram que essa divisão é importante para a compreensão do conteúdo. No entanto, somando-se os dois resultados (52,3\%), pode-se perceber que a maioria dos alunos entende que a divisão em blocos contribui para a fragmentação do conhecimento recebido.

Diante disso, há necessidade de re-disposição do conteúdo da própria disciplina e da própria disciplina com outras, a partir da lógica da transdisciplinaridade, "vale dizer que não se trata do caso da divisão de um mesmo objeto entre (inter) disciplinas diferentes (multi) que o recortariam e trabalhariam seus diferentes aspectos, segundo pontos de vista diferentes, cada 
qual resguardando suas fronteiras $\mathrm{e}$ ficando (em maior ou menor grau) intocadas"(DOMINGUES, 2001).

Foi questionado ainda se era considerado importante que professores de outras disciplinas não diretamente relacionas com a Saúde Mental, trabalhassem o tema durante o curso, 52 $(80 \%)$ responderam que SIM e 13 (20\%), que NÃO, sendo este um importante ponto do trabalho, apontando o necessário enfoque sobre a saúde mental em outras disciplinas.

Dado o período em que os alunos se encontravam durante a pesquisa, certamente já haviam se apercebido da fragmentação em que se dá o processo de construção do saber na Universidade, notadamente no curso de Enfermagem e a necessidade apontada pelos entrevistados de que outras disciplinas trabalhem com o tema da saúde mental, aponta na direção da transdisciplinaridade e, segundo Domingues:[...] o prefixo trans (que além da acepção de através ou de passar por, encerra os sentidos de para além, passagem, transição, mudança, transformação, etc.) aquelas situações do conhecimento que conduzem à transmutação ou ao traspassamento das disciplinas, à custa de suas aproximações e freqüentações (DOMINGUES et al.,2001). transdisciplinaridade, portanto, não tem um objeto próprio de estudo. O prefixo trans diz respeito ao que está ao mesmo tempo entre as disciplinas, através das diferentes disciplinas e além de toda disciplina"(NICOLESCU, 1997).

Para que haja um projeto transdisciplinar, portanto, é preciso que antes seja mudado o sistema de referência. Nicolescu (1997), ao apresentar a metodologia da pesquisa transdisciplinar, aponta seus três pilares: os níveis de realidade, a lógica do terceiro termo incluso e a complexidade (GALHEIGO,1999).

Quando questionados se já tiveram ou tinham intenção em trabalhar com portadores de sofrimento mental, 69,2\% disseram que NÃO e $30,8 \%$ que SIM. Portanto, a maioria dos alunos não tem a intenção de trabalhar com as pessoas com transtorno mental, o que pode ser explicado pela maneira histórica de se cuidar dos loucos. A inserção da enfermagem sempre esteve voltada para a questão da vigilância aos prováveis episódios de agressão e violência,[...] durante muito tempo, o doente mental continuou sendo visto como o louco perigoso que representa um risco para a sociedade. A criação de novos hospitais públicos e privados, a ampliação de outros e o surgimento dos 
primeiros ambulatórios não conseguiu fazer com que a assistência psiquiátrica mudasse, pois a ampliação dos serviços não foi acompanhada de uma mudança na maneira de perceber e tratar o doente (ROCHA, 2008).

Constata-se que prioridade dos alunos não é trabalhar com a saúde mental, reforçando a proposta de uma interação maior entre as diversas disciplinas no campo da saúde, para que a enfermagem venha a sair de sua posição de meramente assistencialista para um conjunto de trabalhadores inseridos em um novo projeto de assistência às pessoas em sofrimento mental, já que a ideia de descentralização está associada à uma reorganização da rede assistencial em saúde, com a extinção progressiva dos hospitais psiquiátricos, genericamente denominados manicômios.

Um aspecto fundamental deste trabalho é a concepção de uma nova prática assistencial, não mais centralizada no objeto 'doença mental', mas no objeto 'existência-sofrimento' em sua relação com a reprodução sociocultural das pessoas (PELBART, 1990).

Esta reforma, segundo Alves (1998), pressupõe uma maior sensibilidade dos programas de saúde mental para com os valores e crenças das comunidades-alvo, bem como um constante diálogo entre serviços e comunidade.

Ainda segundo esse autor, nesse ponto pode-se considerar a questão das crenças e valores que cada um dos alunos tem do que seja a loucura, a pessoa em sofrimento mental e suas peculiaridades, pois, segundo ele, "é importante levar em consideração que as crenças são produtos de ações humanas concretas e servem para justificar determinadas atitudes. Esse fato torna-se mais óbvio quando se move da ótica institucional para a análise de indivíduos e grupos sociais contextualizados no mundo da vida cotidiana (ALVES, 1998).

Em lugares considerados hoje como substitutivos à exclusão nos hospitais psiquiátricos, os dados revelam que a maioria dos estudantes pesquisados ainda tem uma das mais importantes sensações de estranhamento, principalmente quando percebem essas pessoas como muito próximas e à sua frente.

Apesar do preparo teórico recebido em sala de aula, em seus estágios os estudantes estarão convivendo e aprendendo a cuidar de pessoa com transtorno mental.

No exercício de suas funções como estudantes de enfermagem e, 
portanto, como pessoas que vão prestar cuidados a outras em situação de riscodoença, deparam-se com diferentes particularidades, tornando a sensação de estranhamento e espanto a mais citada pelos alunos.

A Enfermagem, na esteira da formação da Psiquiatria, com o surgimento dos hospícios, fez com que o cuidado em relação aos loucos se tornasse um dos aparatos para garantir ordem e harmonia nos lugares da exclusão das pessoas em sofrimento mental.

Citando Ribeiro, "nunca é excessivo lembrarmo-nos que a loucura não é tão só um conjunto de fenômenos psicopatológicos, mas uma relação entre as pessoas, entre saberes e entre poderes, mediada por um imaginário: o imaginário da loucura" (RIBEIRO, 2003).

O espanto e o estranhamento são constatações importantes para a preparação dos estudantes de enfermagem em suas condutas em termos de cuidados às pessoas em sofrimento mental, sendo imprescindível na busca da formação do enfermeiro como profissional da saúde, a orientação no sentido da lógica da não-exclusão, já que:

A lógica da exclusão independente de sua prevalência nas diversas formas e espacialidades que o manicômio sempre pode assumir, não se elimina tão facilmente de uma sociedade, sem que esta última tenha de criar, para si própria um outro sentido e um outro olhar para com a diferença - é a de resgatar a cidadania dos doentes mentais ali onde ela ainda nem se declarou ou zelar pela mesma ali onde ela está, sob a constante vertigem de sua própria fugacidade (RIBEIRO, 2003).

É importante observar e atentar para o fato de que para os entrevistados, um dos principais papéis do enfermeiro refere-se à questão do cuidado, seja aquele prestado pelo profissional ou o prestado pela própria pessoa que sofre.

Na pessoa em sofrimento mental existe perda do ponto de vista subjetivo. Deixa de cuidar de se cuidar. O enfermeiro deve, então, estar preparado para lidar com as novas diretrizes do modelo de atenção à saúde mental que apontam para a desinstitucionalização que, "consiste no desconstruir o paradigma problema-solução, ou seja, a ideia da doença que precisa de cura, em torno da qual se legitima o isolamento, a medicalização, a tutela e a desqualificação do sujeito" (AMARANTE, 1996).

Propõe-se um novo trabalho da enfermagem voltado para o cuidado à pessoa em sofrimento mental, a partir 
da autonomia do sujeito frente às suas questões, para que ele possa se dar conta de que é uma pessoa que sofre, pois segundo Kinhosita:

[...] a questão da doença mental, entendida aí como uma limitação é paradoxal. O sujeito mesmo sendo um doente pode estar saudável, porque a doença se mostra como algum tipo de limitação dada o paciente pode ser saudável, na medida em que busca continuamente superar-se.

Não é buscar a eliminação de uma carência, de um defeito, mas de tentar uma contínua superação deste (KINHOSITA, 1997 apud VIEIRA FILHO, 2006).

Com estes dados, reforça-se a necessidade da formação do enfermeiro em saúde mental voltada para a preparação de um profissional que consiga escutar o sofrimento do indivíduo e trabalhar na construção de possibilidades para o ressurgimento da pessoa em sua potencialidade de cidadã colocada no mundo e diferente dos outros cidadãos em suas particularidades.

A formação do enfermeiro, dadas a condições impostas pelo modelo, pela dicotomia presente em toda a enfermagem, que é a separação entre os saberes de quem executa e de quem coordena o trabalho, precisa estar pautada no referencial do resgate da autonomia dos loucos enquanto pessoas em sofrimento mental, sujeitos em suas diferenças.

\section{Considerações Finais}

O enfermeiro deverá estar apto a escutar a pessoa em sofrimento, acolhêla, e estar pronto para definir sua intervenção de acordo com a lógica do compartilhar saberes e destituir-se de seu próprio saber para dar lugar a um saber novo que virá a partir da escuta de quem sofre e, "compartilhar saberes é exercício contínuo e muito difícil" (ALVES, 1998).

Neste estudo ficou constatado que o encontro dos entrevistados com as pessoas em sofrimento mental é marcado por sensação de estranhamento e espanto, percebida ao longo do curso e historicamente sentida pelas pessoas.

Os loucos, ou as pessoas em sofrimento mental, ou com transtorno mental, ficaram durante séculos relegados a cuidados muito mais relacionados ao vigiar do que ao suprir necessidades do ser humano.

A história comprova que as internações hospitalares representaram um dos meios mais hediondos de exclusão das pessoas que eram 
consideradas loucas e que a loucura foi vista e temida durante muito tempo.

A Enfermagem passou por vários períodos muito obscuros em termos de cuidado às pessoas, contribuindo até para a privação de direitos mais banais do ser humano, trancafiando os loucos em celas e lugares inóspitos.

A loucura e os loucos estiveram, por muito tempo, fechados em suas idiossincrasias, muitas vezes maltratados por suas condições e, a enfermagem foi, muitas vezes, cúmplice dos percalços por que passaram seres diferentes, cumprindo deveres e tarefas estipuladas pelo trabalho.

Na Saúde Mental e no exercício do aprendizado, constata-se a necessidade de um programa de curso voltado para discussão com outras áreas do conhecimento, em uma perspectiva transdisciplinar, um programa que dê suporte ao trabalho do profissional enfermeiro nas novas possibilidades de lidar com a loucura, sendo que uma das propostas é a construção de meios para a discussão transdisciplinar no

\section{Referências}

ALVES, Domingos Sávio. Integralidade nas políticas de saúde mental. Rio de Janeiro: Laboratório de Pesquisas sobre Práticas de
UNIPAM, englobando os vários cursos da área da saúde, com estudos na área das ciências da saúde.

Conclui-se que a preparação do enfermeiro na saúde mental deve estar voltada para novas questões e que este profissional deve estar apto para atuar diante dos novos parâmetros de compartilhamento de saberes, cuidando das pessoas em sofrimento mental com respeito às suas diferenças como pessoas que sofrem.

Neste trabalho, constatou-se a necessidade do trabalho de preparação constante de alunos para enfrentarem a loucura enquanto sofrimento e não mais como seres perigosos e ameaçadores. Registra-se, também, como importante, a mudança de olhares dos alunos após o contato com as pessoas em sofrimento mental, sem as amarras do tradicional 'olhar preconceituoso', demonstrando ser possível a construção de novos tipos de cuidados voltados para a nãoexclusão das pessoas em sofrimento mental, em ambientes que sejam efetivamente lugares de cuidado para a autonomia do sujeito que sofre.

Integralidade em Saúde (LAPPIS), 1998.

AMARANTE, Paulo. $O$ homem e a serpente: outras histórias para loucura e a psiquiatria. Rio de Janeiro:

FIOCRUZ, 1996. 
BAUMAN, Z. O mal-estar da pósmodernidade. Rio de Janeiro: Jorge Zahar, 1998, p.118.

BRANDÃO, Carlos Rodrigues. $O$ que é educação. 12.ed. São Paulo:

Brasiliense, 1984.

BRASIL. Ministério da Saúde. Saúde mental e atenção básica: o vínculo e o diálogo necessários,inclusão das ações de saúde mental na Atenção Básica.

Brasília: 2003

BRASIL. Ministério da Saúde. Saúde mental no SUS: os Centros de Atenção Psicossocial. Brasília:2004.

CABRAL, Álvaro; NICK, Eva. Dicionário técnico de psicologia. São Paulo: Cultrix, 1974. 406p.

CAMPOS, Pedro Humberto Faria; SOARES, Carlene Borges.

Representação da sobrecarga familiar e adesão aos serviços alternativos em saúde mental. Revista de Psicologia, Belo Horizonte, v.11, n.18,p.219-37, dez. 2005.

CAMPOS, C. R. et al. (Org.) Sistema Único de Saúde em Belo Horizonte: reescrevendo o público. São Paulo: Xamã, 1998.

CARVALHO, Maria Teresa. As fronteiras do eu na psicose - o trabalho pioneiro de Paul Federn. Psicologia em Revista, Belo Horizonte, v.9, n.3, p.4358, jun. 2003.

CARVALHO, Olavo. Consciência e estranhamento (Descartes e a psicologia da dúvida - parte II).Aula dada em 1988, transcrita por Fernando Manso e revista por Luciane Amato. Disponível em:<http://www.olavodecarvalho.org>.

CASTEL, R. A ordem psiquiátrica: a idade de ouro do alienismo. Rio de Janeiro: Graal, 1978.
CASTRO, Helenice Saldanha; MATTOS, Cristiana Pittella; CARVALHO, Frederico Feu; BRANT,Paula; LAIA, Sérgio; SOUTO, Simone; ALCKIMIN, Wellerson. A variedade da prática psicanalítica:o valor clínico do estranho, Revista Curinga, Belo Horizonte, v.25, nov. 2007.

CEIA, Carlos. (Ed.). Estranhamento (ostraniene). E-Dicionário de Termos Literários. Lisboa: 2005.Disponívelem: $<\mathrm{http}: / / w w w . f c s h . u$ nl.pt/edtl/verbetes/P/posmodernismo.ht m>. Acesso em: 5 jun. 2008.

CHAVES, MA. Projeto de pesquisa: guia prático para monografia. 4.ed. Rio de Janeiro: WAK, 2007.11

COLVERO, Luciana de Almeida; IDE, Cilene Aparecida Costardi; ROLIM, Marli Alves. Família e doença mental: a difícil convivência com a diferença. Revista da Escola de Enfermagem da USP, SãoPaulo, v.38, n.2, p.197-205, 2004.

DIAS, Mauro Mendes; SANTOS, Ricardo Gomide (Org.). Textos, texturas e tessituras no acompanhamento terapêutico: as psicoses: públicoprivado. São Paulo: Hucitec / Instituto A Casa,2006.

DOMINGUES, Ivan et al. Um novo olhar sobre o conhecimento: a criação do Instituto de Estudos Avançados da UFMG, as pesquisas transdisciplinares e os novos paradigmas. In: DOMINGUES, Ivan(Org.). Conhecimento e transdisciplinaridade. Belo Horizonte: UFMG, 2001.

FERREIRA, Aurélio Buarque de Holanda. Novo dicionário da língua portuguesa. Rio de Janeiro:Nova Fronteira, 1975. 
FRAYSE-PEREIRA, João. $O$ que é loucura. 10.ed. São Paulo: Brasiliense, 2005. (Coleção Primeiros Passos).

GALHEIGO, Sandra Maria. A transdisciplinaridade enquanto princípio e realidade das ações de saúde. In: CONGRESSO BRASILEIRO DE TERAPIA OCUPACIONAL, 6, 1999, Águas de Lindóia. Anais... Águas de Lindóia: [s.n., 1999]

GODOY, Maria Gabriela Curubeto; BOSI, Maria Lúcia Magalhães. A alteridade no discurso da Reforma Psiquiátrica brasileira face à ética radical de Lévinas. Physis, Rio de Janeiro, v.17, n.2, 2007.

GÜNTER, H. Pesquisa qualitativa versus pesquisa quantitativa - Eis a questão. Psicologia: Teoria e Prática da UFB, Brasília, v.22, n.2, p.201-10, maio/ago. 2006.

KEHL, Maria Rita. O tempo e o cão: a atualidade das depressões. São Paulo: Boitempo, 2009. 298p.

KINOSITA, Roberto Tikanori. A experiência de desconstrução manicomial de Santos: Entrevista. In:VIEIRA FILHO, Nilson Gomes (Org.). Clínica psicossocial: terapias, intervenções, questões teóricas.Recife: UFPE, 1998. 308p.

LAKATOS, Eva Maria; MARCONI, Marina de Andrade. Técnicas de pesquisa: planejamento e execução de pesquisas, amostragens e técnicas de pesquisa, elaboração, análise e interpretação de dados. 6.ed. São Paulo: Atlas, 2006. 289p.

MACHADO, William C. A; MOREIRA, Telma Geovanini Almeida; SHOELLER, Soraia Dorneles. História da enfermagem: versões e interpretações. 2.ed. Rio de Janeiro: Revinter, 2002.

MARCONI, Marina de Andrade; LAKATOS, Eva Maria. Metodologia do trabalho científico. 6.ed. São Paulo: Atlas, 2006.

MARTELETO, Regina Maria. Informação, saúde, transdisciplinaridade e a construção de uma epistemologia social. Ciência \& Saúde Coletiva, Rio de Janeiro, v.12, p.576-9, 2007.

MERHY, Emerson Elias. $O$ ato de cuidar como um dos nós críticos 'chaves' dos serviços de saúde.Belo Horizonte: Ibérica, 2005.

MERHY, Emerson Elias; CAMPOS, Gastão Wagner de Souza; CECÍLIO, Luiz Carlos; CECÍlLIO,Luiz Carlos de Oliveira (Org.). Inventando a mudança na saúde. São Paulo: Hucitec, 1994.

NICOLESCU, B. Evolução transdisciplinar da universidade: projeto CIRET UNESCO:1997.Disponívelem:<http://p erso.clubinternet.fr/urcol/ciret/locarmo/l ocapar4.htm>.12

NICOLESCU, B. Manifesto da transdisciplinaridade. Brasília: UNESCO, 2000.

OLIVEIRA, Alice G Botaro; ALESSI, Neiry Primo. O trabalho de enfermagem em saúde mental: contradições e potencialidades atuais. Revista LatinoAmericana de Enfermagem, Ribeirão Preto, v.11,n.3, maio/jun. 2003.

OLIVEIRA, A. G. B.; ALESSI, N. P. Cidadania: instrumento e finalidade do processo de trabalho na reforma psiquiátrica. Ciência e Saúde Coletiva, Rio de Janeiro, v.10, n.1, mar. 2005. Disponível em:<http://www.scielo.br/ scielo,php?script=sci_artex\&prd=s143- 
$81232005000100026 \&$ ing $=$ pt\&nrm $=$ iss o>. Acesso em: 28 jan. 2010.

PASSOS; Izabel C. Friche. Reforma psiquiátrica: as experiências francesa $\mathrm{e}$ italiana. Rio de Janeiro:FIOCRUZ, 2009. 244p. (Coleção Loucura e Civilização).

PELBART, P. P. Manicômio mental: a outra face da clausura. In: LANCETTI, A. (Org.). Saúde e loucura. 2.ed. São Paulo: Hucitec, p.130-8, 1990.

PESSOTI, Isaías. O século dos manicômios. São Paulo: Ed. 34, 1996. $304 \mathrm{p}$.

PORTER, R. Uma história social da loucura. Rio de Janeiro: Jorge Zahar, 1990.

RIBEIRO, Alexandre Simões. Loucura, cidadania e subjetividade: confluências e impasses. RevistaMal-Estar e

Subjetividade, Fortaleza, v.3, n.1, p.96105, mar. 2003.

ROCHA, Rosamaria Luíza de Melo.

Por uma epistemologia do estranhamento, ou como interpretar em situações de limiaridade. Comunicação, Mídia e Consumo, São Paulo, v.3, n.8, p.55-72, nov. 2006.

ROCHA, Ruth Mylius. Enfermagem em saúde mental. 2.ed. atual. ampl. Rio de Janeiro: SENAC Nacional, 2008.

RODRIGUES, Carla. Valores da vida contemporânea. $O G L O B O$, Rio de Janeiro, 24 de outubro de 2009.

Caderno Prosa \& Verso, p.4.

SANCHES, Marsal; RIOUTI, Ricardo Uchida; TAMAI, Sérgio. (Org.). Manejo do paciente psiquiátrico grave. São Paulo: Roca, 2009.
SILVA, Ana Luíza Aranha; FONSECA, Rosa Maria Godoy Serpa da. Processo de trabalho em saúde mental e o campo psicossocial. Revista Latino-Americana de Enfermagem, Ribeirão Preto, v.13, n.3, maio/jun. 2005.

SILVA, Luciene M. O estranhamento causado pela deficiência: preconceito e experiência. Revista Brasileira de Educação, Rio de Janeiro, v.11, n.33, set./dez. 2006.

SILVEIRA, Lauro F. Barbosa. Pensamento científico e experiência cotidiana: uma leitura de Charles Sanders Peirce. Marília: 2005. Texto inédito.

SOUZA, Marta Elizabeth. Atenção em saúde mental / saúde em casa. Belo Horizonte: Secretaria de Estado de Saúde de Minas Gerais, 2006. 238p.

SOUZA, Maurício Rodrigues. A fabricação do estranho em antropologia e psicanálise: notas para um diálogo intertextual. Psychê, São Paulo, ano 10, n.19, p.33-46, set./dez. 2006.

SPAGNUOLO, Regina Stella; GUERRINI, Ivan Amaral. A construção de um modelo de saúde complexo e transdisciplinar. Interface Comunicação, Saúde e Educação, Botucatu, v.9, n.16, p.191-4, 2005.

STEFANELLI, Maguida Costa; FUKUDA, Ilza Marlene Kuae; ARANTES, Evalda Cançado (Org.). Enfermagem psiquiátrica em suas dimensões assistenciais. Barueri: Manole, 2008.

TURGUÊNIEV, Ivan. Primeiro amor. Porto Alegre: L \& PM, 2008. 104p.

VATTIMO, Gianni. O fim da modernidade: niilismo e hermenêutica 
na cultura pós- moderna. São Paulo:

Martins Fontes, 1996.

WALDOW, Vera Regina; LOPES,

Marta Júlia Marques; MEYER, Dagmar
Eestermann. Maneiras de cuidar, maneiras de ensinar: a enfermagem entre a escola e a prática profissional. Porto Alegre: Artes Médicas, 1995. 